\title{
Women Empowerment and the Nutrition Status of Children Aged Between 6-59 Months
}

\author{
Chipili G ${ }^{*}$, Msuya J ${ }^{2}$, Pacific $\mathrm{R}^{2}$, and Majili SZ ${ }^{2}$
}

${ }^{1}$ Department of Nutritional Sciences, Mukuba University of Natural Science, P.O Box 20382, Kitwe, Zambia ${ }^{2}$ Department of Food Technology, Nutrition and Consumer Sciences, Sokoine University of Agriculture, P.O. Box 3006, Morogoro, Tanzania

${ }^{*}$ Corresponding author: Chipili G, Department of Nutritional Sciences, Mukuba University of Natural Science, P.O Box 20382, Kitwe, Zambia, E-mail: chipiligiven@yahoo.com

Citation: Chipili G, Msuya J, Pacific R, Majili SZ (2018) Women Empowerment and the Nutrition Status of Children Aged Between 6-59 Months. J Nutr Health Sci 5(2): 208. doi: 10.15744/2393-9060.5.208

Received Date: April 22, 2018 Accepted Date: June 25, 2018 Published Date: June 28, 2018

\begin{abstract}
Malnutrition remains a concern in the central province, despite being the most productive province in terms of Agriculture. Most studies in the province have not paid attention to the importance of women empowerment and the nutrition outcomes of the population. In light of this knowledge gap, this study focused on the Women's empowerment and the nutrition status of children aged 6-59 months. The study assessed the extent to which women are empowered in agricultural activities. This study sought to determine the association of women empowerment and nutritional status of children aged 6-59 months in Kapiri-Mposhi district in the Central Province of Zambia. A cross-sectional descriptive study was conducted using a structured questionnaire. A total of 99 households were randomly sampled and the nutritional status of one child from each household assessed using anthropometric measurements. A total of 99 children were included in the study. Up to $21 \%$ of the children were stunted; $2 \%$ were wasted; and $9 \%$ underweight. There was a significant relationship between access to credit or income opportunities and Z-scores for wasting (WHZ) ( $\mathrm{p}<0.05)$. This study suggests that further investment into women's access to income may help improve the nutrition status of children.
\end{abstract}

Keywords: Children; Nutrition; Women empowerment

\section{Introduction}

The nutrition status and child survival is influences by the interaction at household level. This interaction is more important in children below the age of five years because they are not yet in school but spend most of the time at home [1]. Given this background women empowerment play a very important role in the nutrition status of under-five children [2].

Women are considered to be empowered if they are highly educated, make decisions, they own goods, have access to income and if they are able to take up leadership positions [2]. The type of food and the time of feeding children are usually determined by mothers. Studies have indicated that feeding and child growth outcome of under-five children is determined by mother [3]. In addition women's participation in household decision has been linked to improvement of under-five children's health $[4,5]$. Furthermore, research shows that a woman's control over financial resources could effectively change the composition of household purchases [6,7]. Women who have control over finances are capable of buying a variety of nutritious foods compared to those who are not.

According to Zambia Demographic Health Survey 2013/2014 the levels of stunting in the central province is unacceptably high. About $43 \%$ children are stunted, 15\% underweight and 5\% wasting [8]. There are policies that look at gender and women's rights at local government level In Zambia. These police are there to provide an enabling environment for the observance of women's right and their involvement in national development. The policies include the National Gender policy and National Health strategic plan $[9,10]$. Furthermore, the Government of the Republic of Zambia (GRZ) recognises the role Non-Governmental Organisations (NGOs) play in providing service for women. Despite this background, there is limited information on women empowerment and the nutrition status of children in Central Province. The primary objective of this study was to assess women empowerment in agricultural activities and its association to child nutrition status. The primary outcome was improved $\mathrm{Z}$ scores in children whose mothers were empowered compared to those who were not. 


\section{Materials and Methods}

\section{Study Site}

The study is part of a macro study 'Implementation of Nutrition Sensitive Agriculture in the Central Province of Zambia' that was conducted in Kapiri-Mposhi a small district of the Central Province [11]. Kapiri-Mposhi is located $-13^{\circ} 58^{\prime} 17.29^{\prime \prime}$ S, 28 $8^{\circ} 40^{\prime}$ $11.46^{\prime \prime} \mathrm{E}$ and has population of 240,648 [12]. The economic base of the district is mainly the agricultural sector. About $90 \%$ of the inhabitants depend on agriculture for their livelihood and most of them are peasant farmers.

\section{Study Design}

A cross sectional survey, both descriptive and analytical in nature was carried out using a pretested structured questionnaire. The questionnaire consisted question on social-demographic characteristics, nutrition status of children and women empowerment.

The sample size was determined by using the prevalence of stunting in Kapiri-Mposhi and Kish's formula for cross sectional surveys was use [13].

The following formula was used to select a sample.

$\mathrm{n}=\mathrm{z}^{2} \times \mathrm{p} \times \mathrm{q}$

$\mathrm{m}^{2}$

Whereby:

$\mathrm{n}=$ desired minimum sample size

$\mathrm{Z}=$ the standard normal deviate corresponding to 95\% Confidence Interval (1.96)

$\mathrm{p}=$ the proportion of an indicator measured

$\mathrm{q}=1-\mathrm{p}$

$\mathrm{m}=$ degree of accuracy or desired precision

-Taking the prevalence of stunting in Central province as $53 \%$ or 0.53 for, z statistic corresponding to $95 \%$ confidence interval for a two-tailed test as 1.96 , and degree of accuracy at 0.05 , the sample size will be:

$\mathrm{n}=(1.96)^{2} \times 0.53 \times 0.47=382$

$(0.05)^{2}$

About 356 (26 had missing data) households were sampled and 108 households with children aged 6-59 months were selected for the study, by the random numbers method. The selected households were drawn from small-scale famers who had at least one child between the ages of 6-59 months. If there was more than one child, only the youngest child was enrolled for the study. Some of the households had missing data making the final sample to be 99 households and 99 children aged 6-59. Verbal consent was obtained from all participants. Confidentiality was assured and participants were free to withdraw from the study at any time.

\section{Data Collection}

The questionnaires comprised mainly of details on household profiles like age, sex, education level and occupation of household members, household size and marital status of the household heads, children's nutrition status of and questions on women empowerment.

\section{Anthropometric Data}

Anthropometric measurements were taken for children aged (6-59) months. The child's date of birth was obtained from the under-five clinic card and was recorded in months. Weight was measured using a salter scale. The scale was hanged on to a secure place and the child's measurements were recorded to the nearest one decimal place. The length/height was measured using a UNICEF wooded length/height board.

\section{Women Empowerment Data}

Data on women empowerment was collected using a questionnaire. Five questions were included in the questionnaire. The questions included women's access to productive resources, access to household income, access to extension services, women's voices in household decisions and women leadership in agriculture programs. Women were asked to respond yes or no to the above questions and multiple answers were allowed. We used a scale of 1-5 to determine women empowerment. Those who scored 4 (yes) and above were considered to be empowered while those who scored 3 (yes) and below were considered not empowered.

\section{Focus Group Discussions (FGDs)}

A total of three Focus Group Discussions were conducted. One had males only, the second one had females only and the third one 
had both males and females. A FGD guide was used to aid the discussion. The discussion focused on the nutrition status of 6-59 moths children and women empowerment. Proceeding of the FGD were recorded by the chief investigator and later transcribed.

\section{Data Analysis}

WHO anthro software was used to compute Z-score (weight-for-age, height-for-age and weight-for-height) according to WHO reference standard [14], taking -2SD as cut-off points (underweight, stunting and wasting). The Statistical Package for Social Scientists (SPSS) version 20 was used to analyze demographic and socio-economic data. Independent t-test was used to establish relationships between women empowerment and the nutrition status of children.

\section{Results}

\section{Characteristic of Study Population}

Most women in the study were married $88 \%$ while $7 \%$ were widowed and $5 \%$ were single parents. About $8 \%$ of the women had no formal education, $26 \%$ attended primary education, $49 \%$ went up to secondary school while $17 \%$ had post-secondary education. The majority of women were between 25-40 (67\%) years of age, 20\% were above 40 while $13 \%$ where below 25 years of age (Table $1)$.

\begin{tabular}{|c|c|c|}
\hline Characteristic & Frequency $(n=99)$ & Percentage \\
\hline \multicolumn{3}{|c|}{ Education level } \\
\hline No Formal Education & 8 & 8 \\
\hline Lower Primary & 26 & 26 \\
\hline Secondary & 48 & 49 \\
\hline Post-Secondary & 17 & 17 \\
\hline \multicolumn{3}{|c|}{ Marital Status } \\
\hline Single & 5 & 5 \\
\hline Married & 87 & 88 \\
\hline Divorced/Widowed & 7 & 7 \\
\hline \multicolumn{3}{|c|}{ Age } \\
\hline Below 25 & 13 & 13 \\
\hline Between $25-40$ & 66 & 67 \\
\hline Above 40 & 20 & 20 \\
\hline
\end{tabular}

Table 1: Distribution of respondents according to their level of education and source of income

\section{Women Empowerment Assessment}

Women empowerment was assessed according to the number of positive responses to the five questions that were included in the questionnaire. If the woman scored three (3/5) the woman was considered not empowered but if the scores were more than 4 then the woman was considered empowered. We assumed that conducting interviews in respondents homes would yield $100 \%$ responses because in the rural communities of Zambia, it is easy to access mothers in their homes compared to meeting them at a specific facility.

More than $70 \%$ had no access to reproductive resources. It was also discovered that very few women held leadership positions in agricultural activities (27\%). Access to extension services was also limited (33\%) because women were thought to grow mostly inferior crops as compared to men who grew cash crops. Access to income opportunities was also limited (32). About 50\% women indicated that they had a voice in household decisions (Table 2). The data from FGDs suggested that women were not empowered in the study area. Most men indicated that if women were empowered in the home the men were going to lose respect from their wives because a man was the head of the house.

\begin{tabular}{|c|c|c|}
\hline Empowerment practice & Frequency (n=99) & Percentage \\
\hline Access to productive resources & 30 & 30 \\
\hline Access to income opportunities or credit & 32 & 32 \\
\hline Women voice in farming decision making & 50 & 51 \\
\hline $\begin{array}{c}\text { Female holding leadership in agricultural } \\
\text { programmes }\end{array}$ & 27 & 33 \\
\hline Access to extension services and information & 33 & 27 \\
\hline
\end{tabular}

Table 2: Reported extent to which women empowerment practices are undertaken in the study area 


\section{Malnutrition Among the Children}

The mean age of the sampled children was 32.5 months, with the youngest being 6 months old and the oldest 59 months old. Overall, $79 \%$ of the children had normal height for their age. The prevalence of stunting among the children was $21 \%$ (Table 3 ). Up to $98 \%$ of the children had normal weight for their height. Prevalence of wasting was $2 \%$ while the prevalence of underweight was $9 \%$. Stunting was lowest in the first year of life and highest in second and third years of life; while underweight and wasting was highest in the fourth year. Prevalence of underweight increased with age from the fourth year of life. No incidence of wasting was observed in the first year of life.

\begin{tabular}{|c|c|c|c|c|c|}
\hline Indicator & $\mathbf{n}$ & $\begin{array}{c}\text { Mean z-scores } \\
\mathbf{\pm S D}\end{array}$ & $\begin{array}{c}\text { Design Effect } \\
(\mathbf{z} \text {-score <-2) }\end{array}$ & $\begin{array}{c}\text { z-scores out } \\
\text { of range }\end{array}$ & Prevalence rate in \% \\
\hline Weight-for-Age (WAZ) & 99 & $-0.5 \pm 0.86$ & 1.00 & 0 & 9 \\
\hline Height-for-Age (HAZ) & 99 & $-1.23 \pm 1.12$ & 1.00 & 0 & 21 \\
\hline Weight-for-Height(WHZ) & 99 & $0.14 \pm 1.05$ & 1.00 & 0 & 2 \\
\hline
\end{tabular}

Table 3: Mean Z-Scores, Design Effects

There is significant displacement of the sample curve to the left of the reference, indicating a poor nutritional situation in the sampled population (Figure 1). The mean Z score of the sample is -1.23 (SD 1.12) indicating a poorly nourished population.

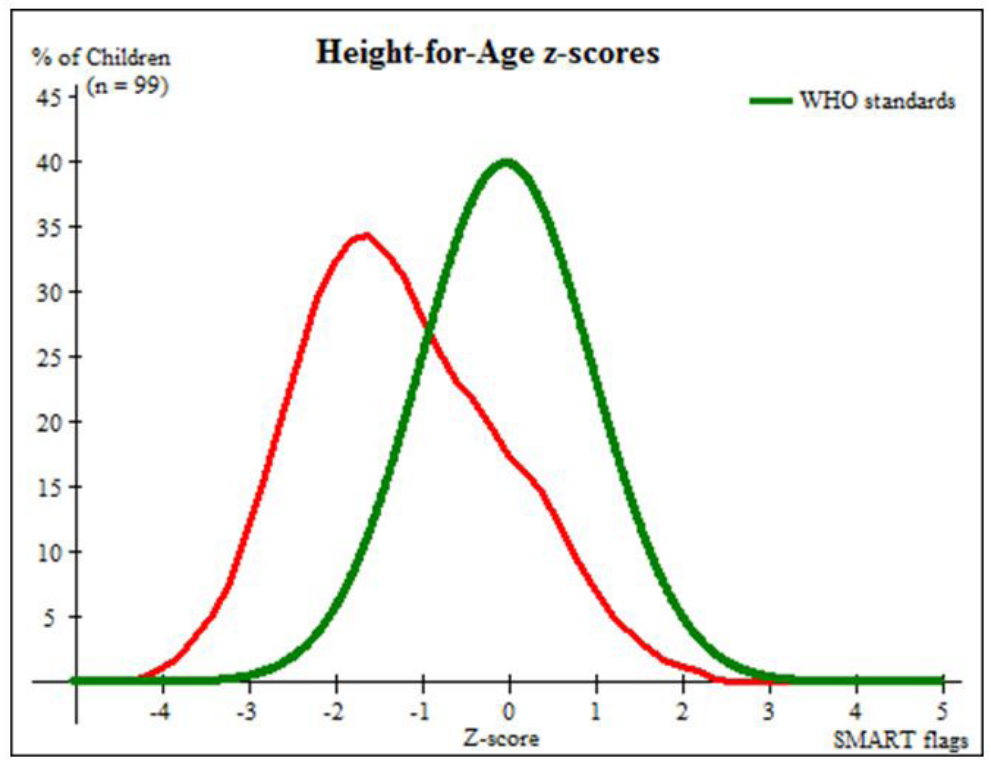

Figure 1: Height for Age Z-scores

\section{Women Empowerment and the Nutrition Status of Under-five Children (6-59 months)}

T-test was performed to compare mean values of various indicators of nutrition status for various practices of women empowerment. Mean values of the t-test variables are presented in Table 4 . Out of the 5 practices that were tested, only $1(20 \%)$ showed a significant relationship with the nutrition status of the under-fives children in the households. It is showing that access to income/credit was positively affecting the WHZ outcome.

\begin{tabular}{|c|c|c|c|c|c|c|c|}
\hline \multirow[t]{2}{*}{ Women Empowerment Indicator } & \multirow[t]{2}{*}{$\mathrm{N}=99$} & \multicolumn{2}{|c|}{ WAZ } & \multicolumn{2}{|c|}{ HAZ } & \multicolumn{2}{|c|}{ WHZ } \\
\hline & & Mean \pm SD & P-value & Mean \pm SD & P-value & Mean \pm SD & P-value \\
\hline Have no access to income/credit & 32 & $-0.66 \pm 0.86$ & 0.64 & $-1.08 \pm 1.15$ & 0.989 & $-0.17 \pm 1.14$ & 0.018 \\
\hline Have access to income/credit & 67 & $-0.34 \pm 0.82$ & & $-1.08 \pm 1.19$ & & $0.32 \pm 0.93$ & \\
\hline
\end{tabular}

Table 4: Relationship between women empowerments and under-five (6-59) nutritional status

\section{Discussion}

A number of studies have demonstrated that women's empowerment is associated with better health outcomes in children [7,1418]. This study found that households that reported to have higher access to income/credit by women was having better scores in weight-for-height (WHZ) of their children. Evidence suggests that women's control over finances is particularly important for household food security and for child outcomes because women tend to invest substantially in nutrition, education, and healthcare 
$[6,7,19,20$,$] . However, other indicators of women empowerment included in this study had no association with the nutrition status$ of children aged 6-59 months. Studies shows that a woman's voice in decision-making is positively associated with the nutrition status of children under the age of five [21-23]. There is evidence that women decision making is not directly associated with nutrition status of children [24]. Our study agrees with the findings because we did not find any association women's voices in household decisions and the nutrition status of children. A study in Nepal found that composition of agricultural production could directly influence the availability and quality of food in the household [25]. This is in line with what this study found. Our study did not find any association between access to productive resources and the nutrition status of children. The other indicator assed was access to extension services, which had no association with improved nutrition status. The results agree with what Duflo found [26].

\section{Strength and Limitation of the Study}

The strength of this study is that it will provide useful information to the Zambian government when formulating and implementing specific rural based interventions to promote women empowerment. The limitation is that not all under-five children were included in the study due to the limited budget.

\section{Conclusion}

This study concluded that there is need for women to have access to finances in order to improve the nutrition status of children in the study area. We further recommend a longitudinal study to be conducted in order to document women activities for a period.

\section{Acknowledgement}

Sokoine University of Agriculture (SUA) Morogoro, Tanzania, Mukuba University of natural Sciences Kitwe, Zambia, Ministry of Agriculture in Zambia, Ministry of Education Central Province, Zambia and Ministry of Health, Central Province, Zambia.

\section{References}

1. Badeke QD, Maina I, Mboganie MA, Muchemi G, Kihoro EM, et al. (2014) Nutritional status of children under five years and associated factors in Mbeere South District, Kenya. Africa Crop Science 22: 1021-9730.

2. Bose S (2011) The effect of women's status and community on the gender differential in children's nutrition in India. J Biosoc Sci 43: 513-33.

3. Bezner Kerr R, Berti P, Chirwa M (2007) Breastfeeding and mixed feeding practices in Malawi: timing, reasons, decision makers, and child health consequences. Food Nutr Bull 28: 90-9.

4. Allendorf K (2007) Do Women's Land Rights Promote Empowerment and Child Health in Nepal? World Development 35: 1975-88.

5. Ross-Suits H (2010) Maternal Autonomy as a Protective Factor in Child Nutritional O Outcome in Tanzania. Public Health Theses, Georgia State University, Georgia.

6. Roushdy R (2004) Intra-household Resource Allocation in Egypt: Does Women's Empowerment Lead to Greater Investments in Children? Economic Research Forum, Cairo, Egypt.

7. Shroff M, Griffiths P, Adair L, Suchindran C, Bentley M (2009) Maternal autonomy is inversely related to child stunting in Andhra Pradesh, India. Matern Child Nutr 5: 64-74.

8. Zambia Demographic Health Survey (2014) Review of the National Health 2013-2014. Lusaka, Zambia.

9. Ministry of Gender and Child development (2014) National Gender Policy. Lusaka, Zambia.

10. Ministry of Health (2011) National Health Strategic Plan (NHSP) (2011-2015). Government of the Republic of Zambia, Lusaka.

11. Chipili G (2015) Implementation of Nutrition-sensitive Agriculture in the Central Province of Zambia. J Nutr Health Sci 3: 207.

12. Central Statistical Office (2012) 2010 Census of Population and Housing Report. Government of the Republic of Zambia, Lusaka, Zambia.

13. Leslie K (1965) Survey Sampling. John Wiley Sons Inc. New York.

14. de Onis M, Garza C, Onyango AW, Borghi E (2007) Comparison of the WHO Child Growth Standards and the CDC 2000 Growth Charts. J Nutr 137: 144-8.

15. Smith LC, Ramakrishan U, Ndjaye A, Haddad L, Martorell R (2002) The importance of women's status for child nutrition in developing countries. Food Nutr Bulle 24: 287-8.

16. Sethuraman K, Lansdown R, Sullivan K (2006) Women's empowerment and domestic violence: the role of sociocultural determinants in maternal and child undernutrition in tribal and rural communities in South India. Food Nutr Bull 27: 128-143.

17. Bhagowalia P, Menon P, Quisumbing AR, Soundararajan V (2012) What dimensions of women's empowerment matter most for child nutrition: Evidence using nationally representative data from Bangladesh. International Food Policy Research Institute, Washington, D.C, USA.

18. Le'pine A, Strobl E (2013) The effect of women's bargaining power on child nutrition in rural Senegal. World Develop 45: 17-30.

19. Cunningham K, Ruel M, Ferguson E, Uauy R (2014) Women's empowerment and child nutritional status in South Asia: a synthesis of the literature. Matern Child Nutr 11: 1-19.

20. Olney DK, Pedehombga A, Ruel MT, Dillon A (2015) A 2-year integrated agriculture and nutrition and health behaviour change communication program targeted to women in Burkina Faso reduces anemia, wasting, and diarrhea in children 3-12.9 months of age at baseline: a cluster-randomized controlled trial. J Nutr 145: 1317-24.

21. Scantlan J, Previdelli A (2013) Women's Empowerment and Childhood Malnutrition in Timor-Leste: A Mixed-methods Study. Mercy Corps, Portland, Oregon. 22. Shroff MR, Griffiths PL, Suchindran C, Nagalla B, Vazir S, et al. (2011) Does Maternal Autonomy Influence Feeding Practices and Infant Growth in Rural India? Soc Sci Med 73: 447-55. 
23. Fantahun M, Berhane Y, Wall S, Byass P, Hogberg U (2007) Women's involvement in household decision-making and strengthening social capital-crucial factors for child survival in Ethiopia. Acta Paediatr. 96: 582-89.

24. Shively G, Sununtnasuk C (2015) Agricultural Diversity and Child Stunting in Nepal. J Develop Stud 53:1078-96.

25. Duflo E (2012) Women Empowerment and Economic Development. J Econ Lit 50: 1051-79.

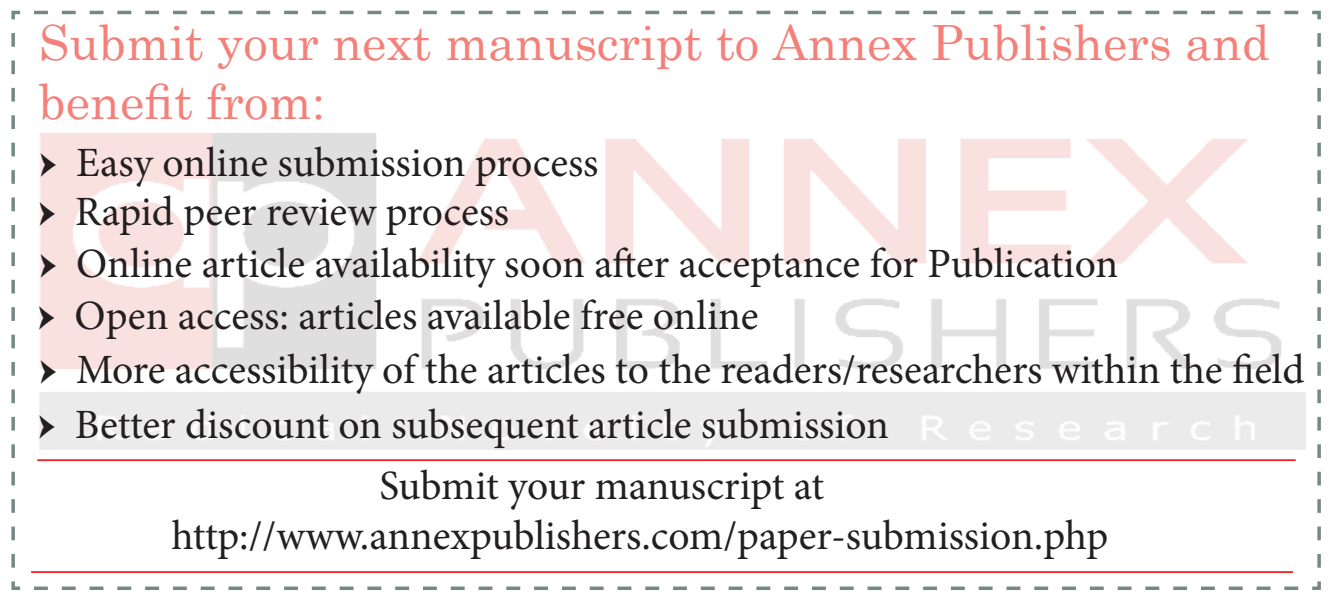

